\title{
THE LARVA OF ACANTHOGNATHUS (HYMENOPTERA: FORMICIDAE)
}

\section{By George C. Wheeler ${ }^{1}$ and Jeanette Wheeler ${ }^{2}$}

In 1953 Brown divided the tribe Dacetini into four subtribes: Dacetiti, Orectognathi, Epopostrumiti and Strumigeniti. After studying the larvae of eight dacetine genera (Daceton, Orectognathus, Epopostruma, Mesostruma, Alistruma, Clarkistruma, Strumigenys and Smithistruma) representing all four subtribes, we concluded (1954) that the larval similarities and differences confirmed the grouping of the adults. But now, alas, our study of the larva of Acanthognathus forces us to revise our conclusion.

\section{Genus Acanthognathus Mayr}

Thorax and first abdominal somite strongly curved ventrally, remainder of abdomen straight; diameter increasing from head to mesothorax, decreasing slightly through metathorax and abdominal somite I, then increasing rapidly to abdominal somite V. Posterior end broadly rounded. Anus with a small posterior lip. Body hairs short to long, moderately numerous. Of three types: (I) bifid with the branches long, on the dorsal surface; (2) nearly straight, with the distal half finely denticulate, on the ventral surface and a few in a transverse row around the middle of each thorax somite and abdominal somites IX and $X$; (3) anchor-tipped, with long flexuous shaft, four in a row across the dorsum of each abdominal somite IVIII. Antennae small, each with three sensilla. Head hairs moderately numerous, moderately long, denticulate. Mandibles long and narrow.

\section{Acanthognathus rudis Brown and Kempf*}

Submature. Length (through spiracles) about $2.6 \mathrm{~mm}$. Thorax and first abdominal somite strongly curved ventrally, remainder of abdomen straight. Diameter increasing from the head to mesothorax, decreasing slightly through metathorax and first abdominal somite, then increasing rather rapidly to a maximum at abdominal somite $\mathrm{V}$.

\footnotetext{
${ }^{1}$ Research Scientist, Whittell Forest, University of Nevada.

${ }^{2}$ Research Associate, Desert Research Institute. Address of both authors: Laboratory of Desert Biology, Desert Research Institute, University of Nevada System, Reno, Nevada 89507.

Manuscript received by the editor May 11, 1969

* See previous article, this issue.
} 
Posterior end broadly rounded. Anus ventral and with a small posterior lip. Spiracles small; the mesothoracic the largest. Integument of ventral surface of thorax and first three abdominal somites with minute spinules in transverse rows. Body hairs short to long, moderately numerous. Of three types: (I) about $0.09 \mathrm{~mm}$ long, bifid with the branches long, alveolus and articular membrane lacking, on the dorsa of all somites; (2) 0.09-0.22 mm long, nearly straight, distal half finely denticulate, on the ventral surface of each somite and a few of the longest in a transverse row around the middle of each thoracic somite and abdominal somites IX and $\mathrm{X}$; (3) 0.19-0.26 mm long, with flexuous shaft and a small anchor-tip, four in a transverse row across the dorsal surface of each abdominal somite I-VIII, the shaft becoming shorter and straighter posteriorly. Cranium subhexagonal in anterior view and with the occipital border straight. Antennae small, with three sensilla each bearing a minute spinule. Head hairs moderately numerous, 0.08-0.I I mm long, with numerous minute denticles. Labrum twice as broad as long, bilobed due to a median impression of the ventral border; anterior surface of each lobe with seven sensilla on and near the ventral border; ventral border with short rows of minute spinules; middle of posterior surface densely spinulose, the spinules minute and in long subparallel subtransverse rows, four sensilla near each ventrolateral corner. Mandibles large, heavily sclerotized; narrowly subtriangular in anterior view; lateral portion thick and ending in a long sharppointed apical tooth, which is curved medially; medial portion of apical half thin and blade-like, with two sharp pointed subapical teeth. Maxillae short and lobose; no spinules seen; palp a slender peg on a broad base, with two apical, two lateral and one basal sensilla, the lateral encapsulated, the others bearing a spinule each; galea a slender subcone with two apical sensilla, each of which bears a spinule. Labium with numerous minute spinules in short arcuate rows; palps short and peg-like with two apical two lateral and one basal sensilla; with an isolated sensillum between each palp and the opening of the sericteries; the latter a transverse slit in a depression. Hypopharynx spinulose, the spinules minute and in short arcuate rows.

Very Young Larva. Length (through spiracles) about $0.67 \mathrm{~mm}$. Generally similar to the submature larva, except in the following details:- Body hairs mostly long, sparse. Of four types: (I) 0.04$0.13 \mathrm{~mm}$ long, slightly curved to flexuous, with many minute denticles, the longest with alveolus and articular membrane; (2) about $0.23 \mathrm{~mm}$ long, with flexuous shaft and small anchor-tip, four in a row across the dorsum of each abdominal somite II-V; (3) 0.07- 

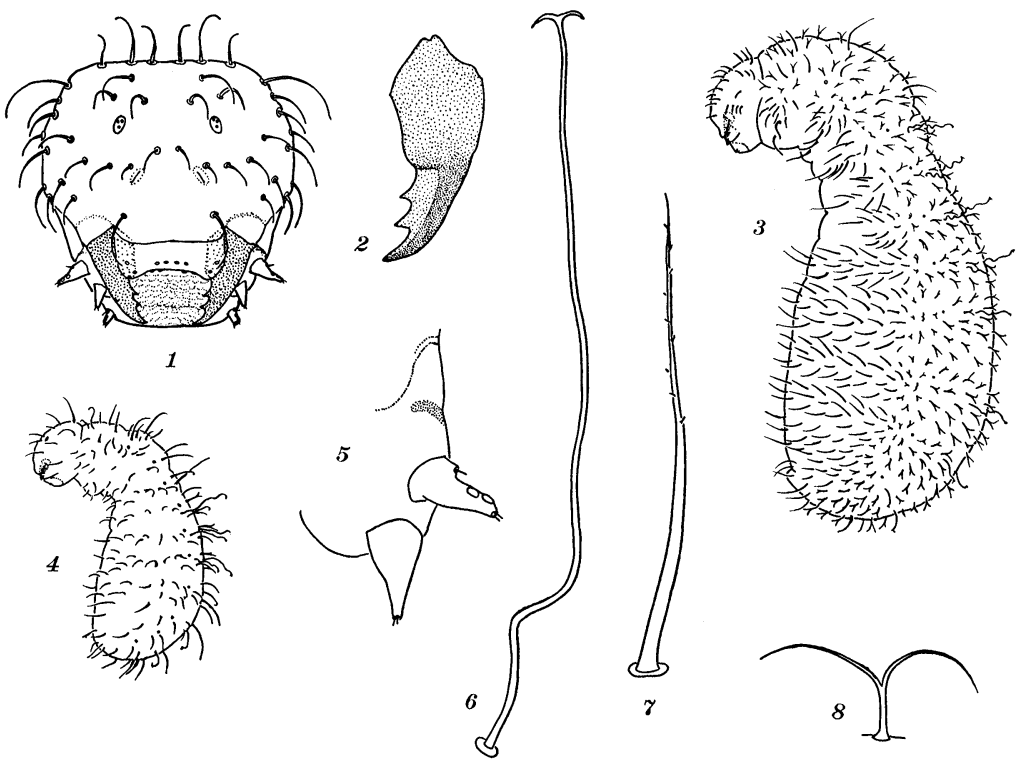

Figs. 1-8. Acanthognathus rudis. 1 . head in anterior view, $x 74 ; 2$. left mandible in anterior view, $x 155$; 3. submature larva in side view, $x 22$; 4. very young larva in side view, $x 22$; 5 . left maxilla in anterior view, $\mathrm{x} 206$; 6-8. three types of body hairs on submature larva, x260.

0.1 $8 \mathrm{~mm}$ long, on abdominal somites VI-IX, with a recurved small anchor-tip; (4) 0.04-0.07 mm long, bifid, with a slightly curved shaft, a few on the dorsum of each abdominal somite. Integument of abdominal somites IX and $\mathrm{X}$ and of the ventral surface of the thorax and first three abdominal somites with minute spinules in short transverse rows. Cranium transversely subelliptical in anterior view.

Material studied: I 8 larvae from Brazil, collected by K. Lenko, courtesy of Dr. W. W. Kempf.

Brown placed Acanthognathus in the Dacetiti along with Daceton, because the adults have ten funicular segments; but the larva of Daceton stands apart from all other known dacetine larvae with respect to body shape, abundance of body hairs and lack of medial mandibular teeth, whereas the larva of Acanthognathus shares most of the tribal characters (Wheeler and Wheeler I954 p. 122). The only significant character shared with Daceton is head hairs moderately numerous instead of sparse.

The larva of Acanthognathus is perhaps most closely related to 
Alistruma: both share body shape, postanal lip, mandibular blade and conical galea, in addition to most of the tribal characters. The next would be Clarkistruma with which it shares body shape and mandibular blade.

In our key to the genera (I960 p. I09) Acanthognathus would come under group $\mathrm{D}$ but would not fit the key below that. It would be in a rubric by itself, because the profile is aphaenogastriform, the mandibles are podomyrmiform and hooked hairs are present.

Brown, W. L.

\section{Literature Cited}

1953. A preliminary report on dacetine ant studies in Australia. Ann. Ent. Soc. Amer. 46: 456-471.

Wheeler, G. C., and Jeanette Wheeler

1954. The ant larvae of the myrmicine tribes Basicerotini and Dacetini. Psyche 61: 111-145.

1960. The ant larvae of the subfamily Myrmicinae. Ann. Ent. Soc. Amer. 53: 98-110. 

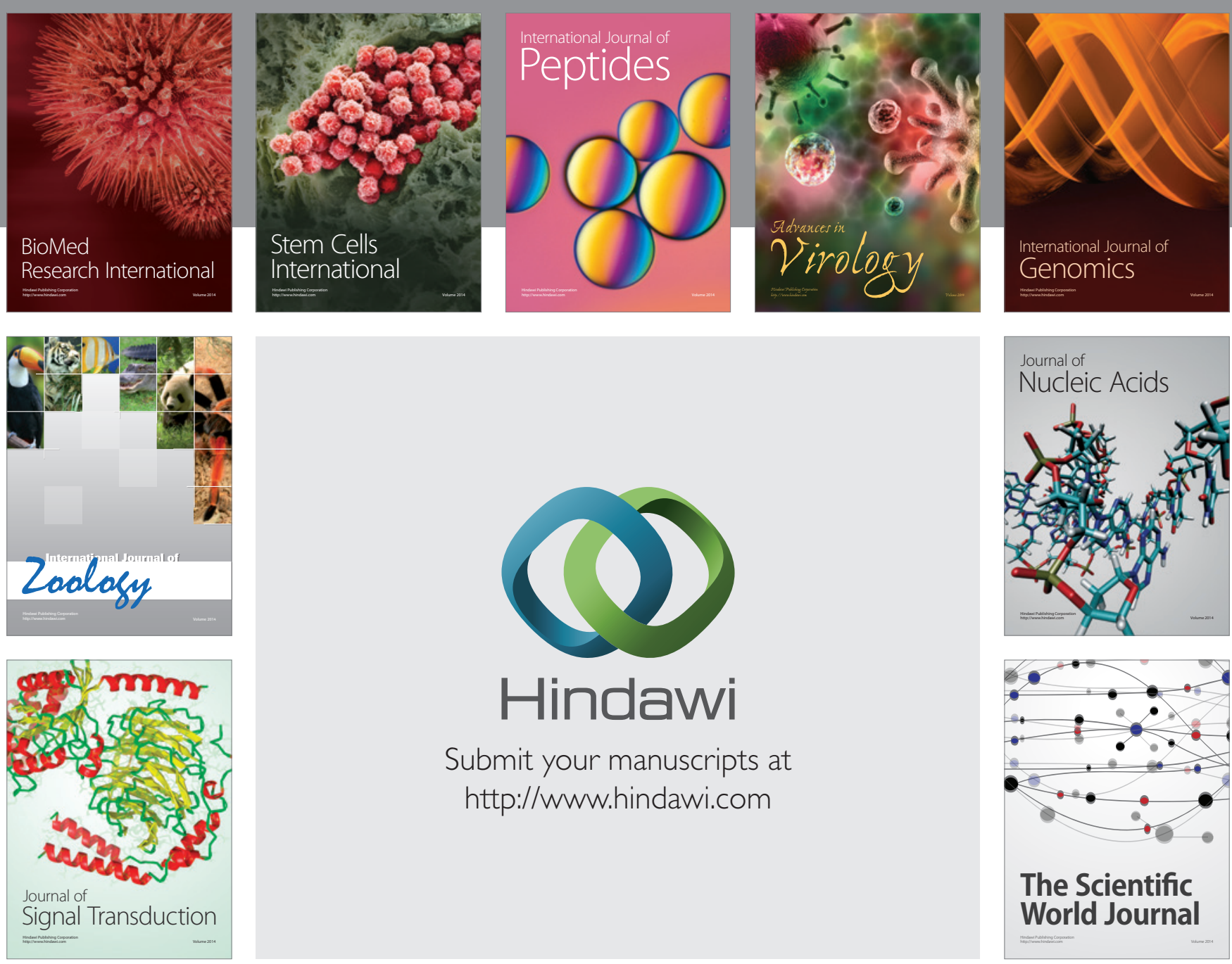

Submit your manuscripts at

http://www.hindawi.com
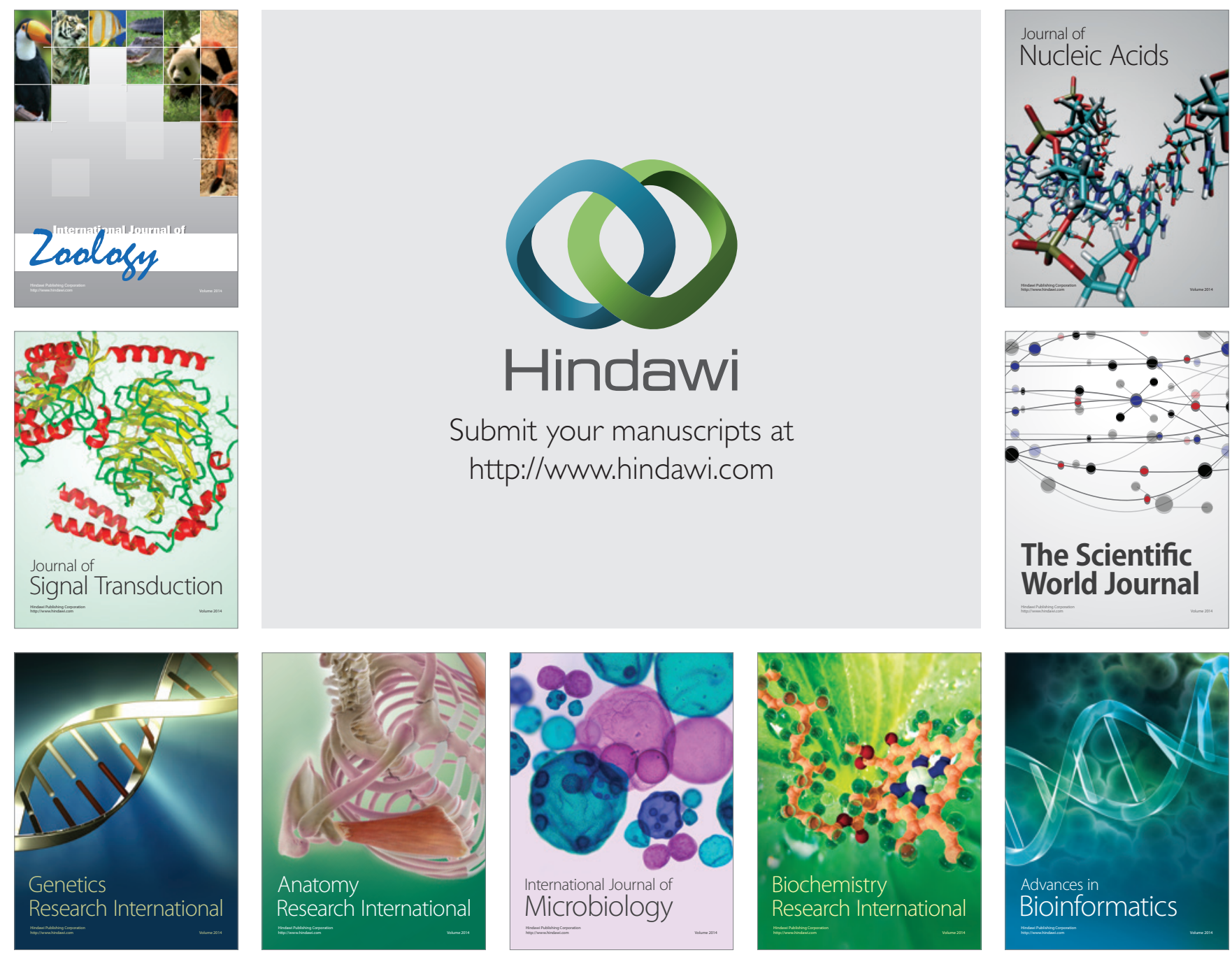

The Scientific World Journal
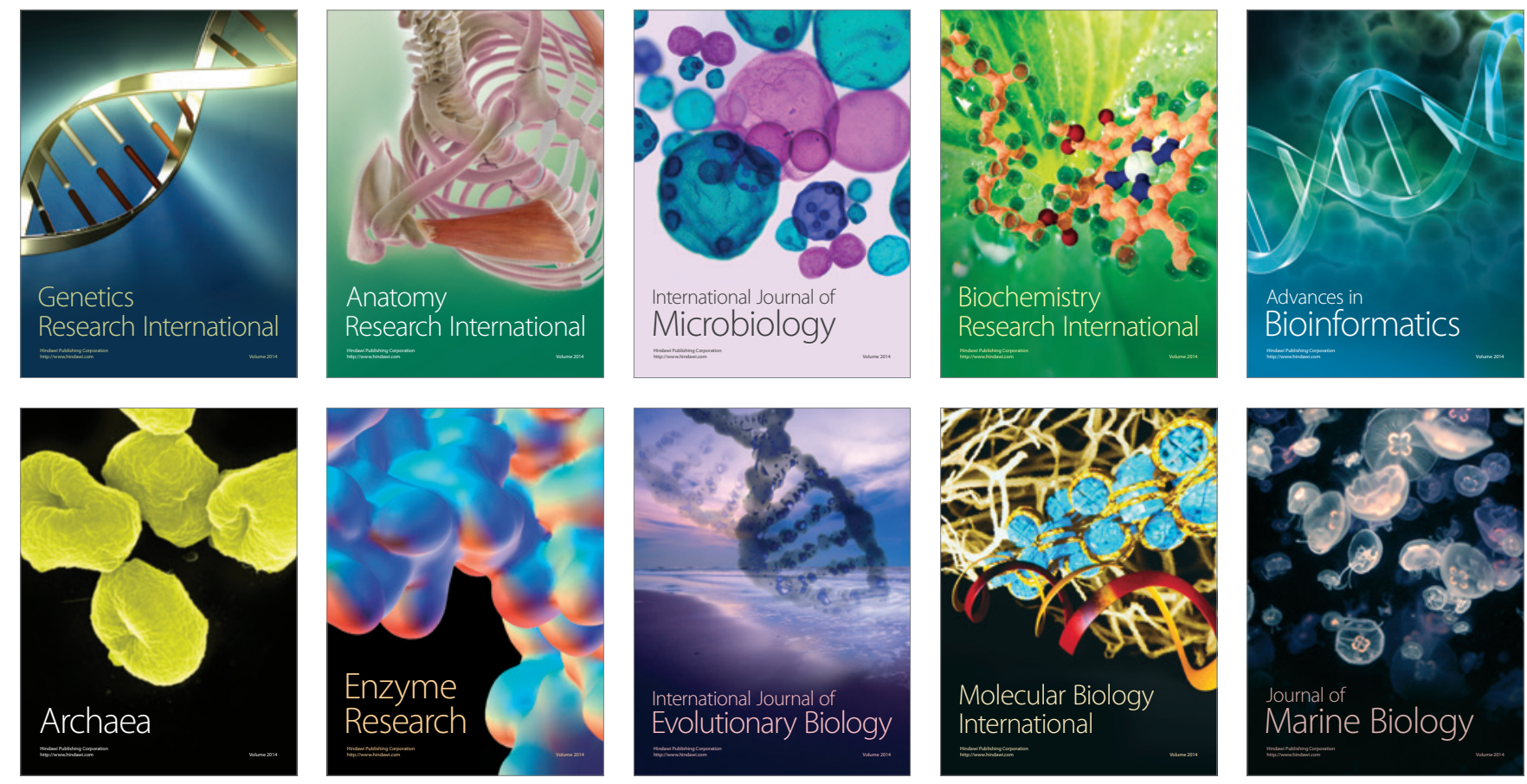